\title{
O Impacto da Sucessão de Cargos na Empresa
}

\author{
Adriana Angelim Mota ${ }^{(1)}$; Maria Paula Silvestre Campelo ${ }^{(2)}$; José Leandro de Almeida Neto ${ }^{(3)}$
}

\begin{abstract}
Resumo: O presente artigo teve o objetivo de identificar o impacto causado pela sucessão tácita de cargos em uma empresa de calçados de Juazeiro do Norte. Em busca de alcançar o aludido objetivo, utilizou-se pesquisa bibliográfica em livros e artigos e pesquisa de campo através de um questionário aplicado em todos os níveis hierárquicos da organização. Alcançou-se o seguinte resultado: A sucessão tácita de cargos leva à alta rotatividade, causando prejuízos com a demissão e recrutamento e seleção de pessoal, além de déficit em produtos e serviços da organização.
\end{abstract}

Palavras-Chave: Cargos, Sucessão, Organização

\section{The Impact of Succession Positions in the Company}

\begin{abstract}
The aim of this article was identifying the impact caused by the tacit succession of jobs at a shoe company in Juazeiro do Norte in its pursuit to reach the cited aim; a bibliographic search was performed in books and articles and in field search through a questionnaire which was applied in all the hierarchical levels of the organization. The following results were reached: The tacit succession of jobs leads to a high turnover of positions, causing damage with the dismissal and recruitment and selection of staff, as well as deficit in goods and services in the organization.
\end{abstract}

Keywords: Jobs, succession, organization

\footnotetext{
${ }^{1}$ Adriana Angelim Mota é Pós graduada em Gestão Estratégica de Pessoas pela Faculdade Leão Sampaio. E-mail: adriana_angelim@hotmail.com;

${ }^{2}$ Maria Paula Silvestre Campelo é Pós graduada em Gestão Estratégica de Pessoas pela Faculdade Leão Sampaio.

E-mail: paulascampelo@ hotmail.com;

${ }^{3}$ José Leandro de Almeida Neto é Pós graduado em Gestão Estratégica de Pessoas pela Faculdade Leão Sampaio.

E-mail: leandro@leaosampaio.edu.br
}

\section{Introdução}

A gestão de recursos humanos está em processo de expansão no Brasil e muitas organizações não possuem um sistema de gestão de pessoas estruturado. Devido esse motivo não há na maioria das empresas um sistema de cargos e salários. 
Através desse trabalho pretende-se constatar qual o impacto gerado por esta prática na vida dos colaboradores e para o resultado organizacional. Entre esses problemas existe a sucessão tácita de cargos. Objetiva-se vislumbrar através deste estudo as conseqüências resultantes desses modelos de administração.

Por outro lado quando há um plano claro e objetivo, o funcionário tem como planejar sua carreira dentro da organização, os mesmos se sentem valorizados e buscam sempre a excelência no que fazem, proporcionando assim a geração de valor para si mesmo e para a empresa, valor esse intelectual e financeiro.

Busca-se também identificar ao longo de estudos voltados para a cadeira de Gestão de Cargos, Salários e Sistema de benefícios, quais os problemas gerados pela sua falta nas organizações.

Seguindo esta linha de pensamento, foi realizada uma pesquisa bibliográfica e de campo, para analisar o quanto este problema pode impactar no resultado organizacional e nos lucros da empresa, como também o planejamento estratégico pode ser um grande aliado na construção e implantação do plano de cargos.

\section{Gestão de Recursos Humanos e o Contexto Atual}

A administração de recursos humanos foi desencadeada a partir da experiência de Hawthorne, desenvolvida por Elton Mayo em 1927 nos EUA. Esta teve como objetivo inicial o estudo das condições ambientais versus produtividade. Em consonância com Chiavenato ( 2004 p.128)

O nível de produção não é determinado pela capacidade física ou fisiológica do empregado (como afirmava a Teoria Clássica), mas por normas sociais e expectativas grupais... Se o empregado apresentar excelentes condições físicas e fisiológicas para o trabalho e não estiver socialmente integrado, sua eficiência sofrerá a influência de seu desajuste social.

Segundo Elton Mayo pode-se concluir no decorrer do estudo que esses fatores não eram determinantes para o aumento da produtividade, mas sim quando existiam condições favoráveis para a integração social, valorização do cargo ocupado e recompensas sociais.

No Brasil essa visão está se consolidando de forma lenta e gradativa, mas pode-se enxergar a procura cada vez mais elevada do mercado por profissionais que atuem na área de Gestão de Pessoas, pois os mesmos exercem um diferencial estratégico para obtenção de

Id en line Revista de Psicologia. Ano 7, No. 20, Julho/2013 - ISSN 1981-1179.

Edição eletrônica em http://idonline.emnuvens.com.br/id 
resultados em todos os níveis organizacionais e em diversos tipos de empresas, sejam elas regionais, nacionais ou multinacionais.

A Gestão de Recursos Humanos tem por desígnio principal aliar os objetivos organizacionais com o dos colaboradores gerando assim motivação. Através desta motivação a empresa obtêm elevação em seus resultados financeiros. Além disso, existem outras finalidades não menos importantes, a exemplo disso pode-se citar as grandes mudanças do mercado sendo de fundamental importância que as organizações se adaptem a estas, por sua vez os funcionários também sofrem pressões para apresentar resultados esperados, neste contexto os gestores de pessoas devem criar estratégias para que a organização atinja seus objetivos através do trabalho dos funcionários, pois stress é sinônimo de baixa na produtividade.

\section{Subsistemas da Gestão de Recursos Humanos}

Ao longo dos estudos realizados na área de $\mathrm{RH}$, surgiu a necessidade da criação de subsistemas para melhor compreendê-la, partindo do pressuposto que a organização é um sistema, sendo este um conjunto de partes interdependentes e interligadas com um objetivo. As partes ou subsistemas da Gestão de Recursos Humanos são: Provisão, Aplicação, Manutenção, Treinamento e Desenvolvimento, Avaliação e Controle. Segue detalhamento de cada um:

a) Provisão: medidas que são tomadas para que novos recursos humanos sejam agregados a organização e sintam-se parte dela, envolvendo portanto ações relacionadas ao recrutamento, seleção e treinamento de integração.

b) Aplicação: estruturar a gestão de cargos e alocar os recursos adequadamente para proporcionar satisfação e agregação de valor. Atualmente essa colocação está se dando em sua maioria de forma empírica, ou seja, não há um estudo detalhado do cargo que irá ser ocupado descriminando suas atribuições para que o ocupante soubesse o que se espera dele, e também uma avaliação do possível contratado ou promovido para identificar neste as habilidades que o cargo exige.

c) Manutenção: promover condições para que as necessidades pessoais do capital humano sejam atendidas de forma a reter talentos.

d) Treinamento e desenvolvimento: treinar os funcionários para a obtenção de habilidades pertinentes a execução de suas atribuições.

e) Avaliação e Controle: obtenção de informações para formulação de indicadores que apontem as melhorias que se fazem necessárias aos funcionários e a organização.

Id en line Revista de Psicologia. Ano 7, No. 20, Julho/2013 - ISSN 1981-1179. 


\section{Gestão De Cargos}

Diante das informações anteriores, busca-se inicialmente se aprofundar no subsistema de aplicação, direcionando o enfoque para a gestão de cargos. O cargo se constitui do conjunto de funções e atribuições exercidas por um profissional nas organizações, o mesmo representa a posição hierárquica ocupada pelo colaborador considerando os requisitos e responsabilidades.

Com relação aos requisitos Paschoal (2010 p.28) informa que "devem ser especificadas as qualificações requeridas pelo cargo, suficientes para que o ocupante consiga desempenhar com sucesso as funções.” Já as responsabilidades estão relacionadas às funções do cargo, estando inclusive ligadas às habilidades necessárias para a execução eficiente da função.

No que diz respeito ao plano de cargos, pode-se dizer que é o alcance e o funcionamento de um sistema de administração de cargos e salários onde o mesmo de acordo com Paschoal (2010, p.18) é composto por cinco elementos básicos, que são: Informação sobre cargos; cargos hierarquizados; informações sobre o mercado; política salarial interna; estrutura salarial;

A primeira coisa que se pode fazer para que o plano de cargos e salários seja efetivamente eficaz é um programa de implementação do mesmo, que precisa ser iniciado com a hierarquização dos cargos de acordo com a pirâmide dos níveis hierárquicos, adequando o cargo de acordo com a sua condição na organização. Após a pirâmide completa deve-se elaborar o organograma, este irá mostrar claramente quem está subordinado a quem e onde cada cargo encontra-se no nível da empresa. Com esses dois grandes aliados se pode agora iniciar a descrição dos cargos, que deve ser composta pelos seguintes itens, de_acordo com Paschoal (2010 p.22):

Denominação dos cargos, código do cargo, localização departamental, posição na estrutura, objetivo do cargo, escopo da área, funções principais, funções do titular, contatos, dimensões, requisitos, responsabilidade, complexidades, liberdade de ação e condições de trabalho.

Posteriormente se procede a estruturação dos salários que irá levar em consideração a pesquisa salarial no mercado de trabalho e a política salarial da organização, onde a mesma irá definir qual será o seu parâmetro.

Com todos esses passos realizados será possível perceber o impacto e os benefícios que o plano de cargos e salários causa. O gestor maior terá uma visão holística das atividades desempenhadas por cada colaborador dentro da empresa, também poderá suceder a estruturação da matriz de treinamentos e avaliação da produtividade.

Id en line Revista de Psicologia. Ano 7, No. 20, Julho/2013 - ISSN 1981-1179.

Edição eletrônica em http://idonline.emnuvens.com.br/id 
De acordo com o que foi exposto é perceptível que o plano é a base para a realização e implantação de um sistema de recursos humanos eficaz.

\section{Sucessão Tácita}

Com base nas informações anteriormente apresentadas, evidencia-se a sucessão tácita como um fenômeno que ocorre nas organizações que não possuem um Plano de Cargos e Salários definido, se caracterizando quando um funcionário irá ser provido e não são avaliadas as suas habilidades e competências, que são, conforme Carbone et al (2010 p.43):

\footnotetext{
A competência, então, é aqui entendida não apenas como o conjunto de conhecimentos, habilidades e atitudes necessários para exercer determinada atividade, mas também como o desempenho expresso pela pessoa em um dado contexto, em termos de comportamentos e realizações decorrentes da mobilização e aplicação de conhecimentos, habilidades e atitudes no trabalho.
}

Essas aptidões por sua vez não são confrontadas com os requisitos que o cargo exige, gerando para a organização desgaste e aumento de custo, pois o funcionário pode não estar apto a ocupar o cargo, o que pode impactar na redução da produtividade e insatisfação por parte do colaborador.

Algumas empresas sentem a necessidade de justificar um aumento de salário aos seus funcionários através de uma promoção, quando o mesmo poderia acontecer através de uma gratificação por desempenho ou antiguidade, sem gerar uma realocação indevida do mesmo.

Destaca-se que o colaborador que possui a produtividade elevada em um determinado cargo não garante que o mesmo desempenho ocorra em outra função para a qual este pode não estar apto o que certamente causará insatisfação.

\section{Método}

O tipo de pesquisa é definido como exploratória e bibliográfica. Para realizar este estudo científico foi necessário a utilização do método de pesquisa exploratório por se tratar de um assunto ainda pouco difundido e estudado. Tendo sido executado através de pesquisa bibliográfica em vários livros e artigos das áreas de administração e de Recursos Humanos e por pesquisa de campo feita através de questionário para coleta de dados aplicado em uma

Id en line Revista de Psicologia. Ano 7, No. 20, Julho/2013 - ISSN 1981-1179. Edição eletrônica em http://idonline.emnuvens.com.br/id 
organização do ramo de calçados de cidade de Juazeiro do Norte-CE, que não possui um Plano de Cargos e Carreiras implantado, com o intuito de investigar o impacto que a falta do referido plano pode causar no resultado final das organizações.

A pesquisa se deu através de perguntas diretas com alternativas de sim ou não. Este método foi utilizado por esta empresa, que vale ressaltar é do ramo de calçados e possui em grande parte do seu quadro de colaboradores um número considerável de pessoas que não possuem um nível elevado de instrução (chão de fábrica), houve também a preocupação de simplificar o conteúdo das perguntas que estivessem inteligíveis ao público alvo.

\section{Análise e Discussão dos Resultados}

O questionário constava de cinco (05) perguntas objetivas e foi aplicado em membros dos níveis estratégico, tático e operacional, embora tenha-se obtido uma amostra reduzida em razão de dificuldades na obtenção das informações, configurou-se o suficiente para delinear o propósito do estudo.

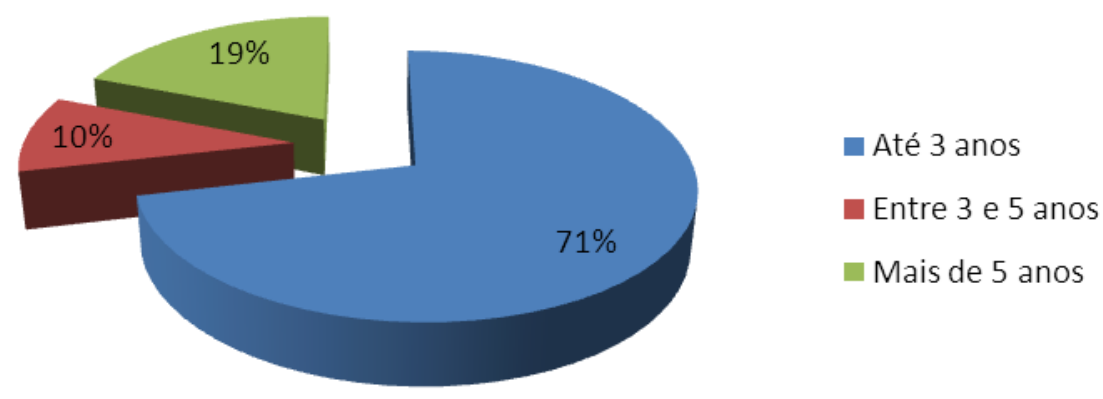

Gráfico 01: Gráfico do percentual do tempo que os colaboradores entrevistados prestam serviço a empresa. Fonte: Pesquisa realizada em uma empresa do ramo calçadista de Juazeiro do Norte.

Conforme pode-se observar no gráfico abaixo, perguntados sobre o tempo de permanência na empresa, a maioria dos colaboradores são novatos, o que revela indícios de rotatividade. O mesmo também mostra a fase crítica de carreira nesta organização que é a faixa 
entre 3 a 5 anos, onde o número de funcionários é bem reduzido. A parcela com mais de 5 anos apresenta o intermédio da quantidade de pessoas.

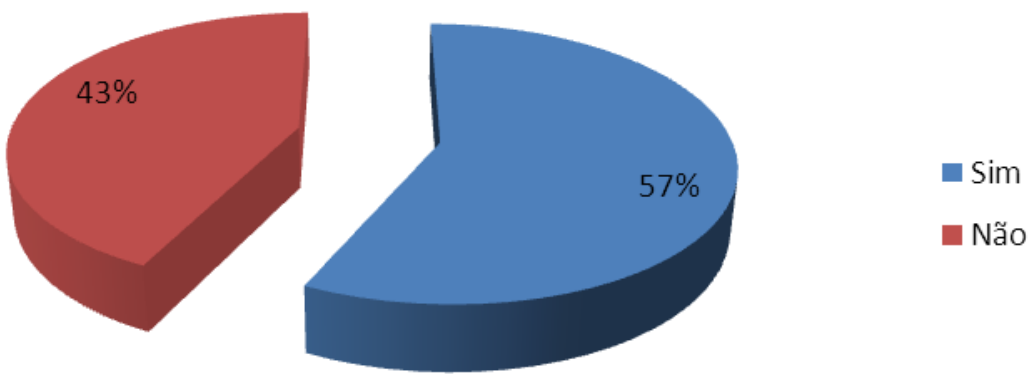

Gráfico 02: Gráfico do percentual dos entrevistados que permanecem no cargo para o qual foi contratado.

Fonte: Pesquisa realizada em uma empresa do ramo calçadista de Juazeiro do Norte.

Como se pode ver no gráfico acima, a maioria dos colaboradores que responderam a pesquisa continuam no cargo para o qual foram contratados. Este gráfico é de suma importância, pois revela a o fator mais importante para a pesquisa que são aqueles que não mais permanecem no cargo ao qual foram contratados.

Id en lime Revista de Psicologia. Ano 7, No. 20, Julho/2013 - ISSN 1981-1179. Edição eletrônica em http://idonline.emnuvens.com.br/id 


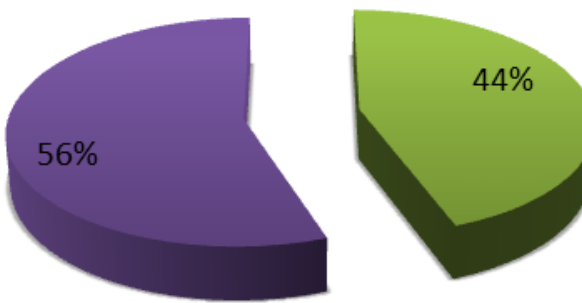

- Sim

— Não

Gráfico 03: (gráfico apresenta em percentual quais funcionários se adaptaram ao cargo)

Fonte: Pesquisa realizada em uma empresa do ramo calçadista de Juazeiro do Norte.

De acordo com o gráfico acima se pode ver que mais da metade dos colaboradores não foram treinados para a mudança, sendo este um erro grave de realocação de pessoas, pois se sabe que é parte fundamental da mudança de cargo o treinamento nos procedimentos operacionais e acima de tudo o acompanhamento para verificar se aquele colaborador está adaptando-se aos novos processos e se está apresentando resultado.

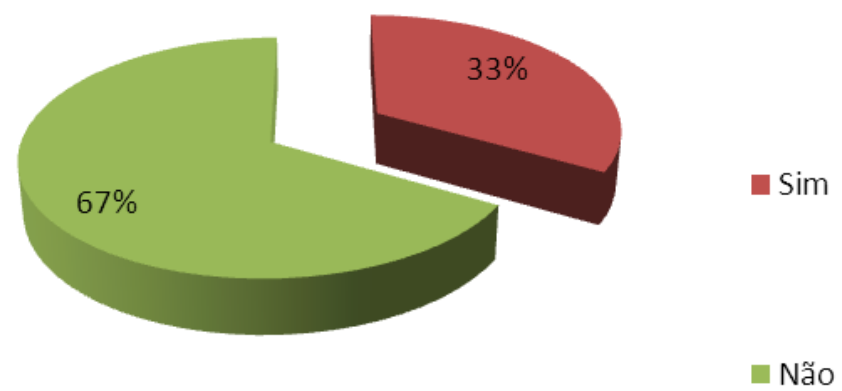

Gráfico 04: Gráfico do percentual dos funcionários que não se adaptaram a mudança cargo.

Fonte: Pesquisa realizada em uma empresa do ramo calçadista de Juazeiro do Norte.

Id en line Revista de Psicologia. Ano 7, No. 20, Juhho/2013 - ISSN 1981-1179.

Edição eletrônica em http://idonline.emnuvens.com.br/id 
Acima segue o quadro que demonstra com clareza que por não serem observadas as habilidades antes da mudança, por em parte não haver treinamento para os transferidos, os mesmos não encontram-se satisfeitos com a mudança,mostrando assim que a realocação de forma incorreta gera, sim, prejuízos para a organização.

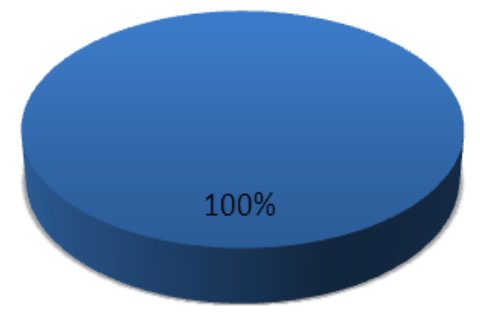

Gráfico 05: Gráfico do percentual dos funcionários se sentiriam motivados com a implantação do plano de cargos. Fonte: Pesquisa realizada em uma empresa do ramo calçadista de Juazeiro do Norte.

Observa-se de acordo com o gráfico acima, que todos os colaboradores responderam que gostariam da implantação de um plano de cargos e salários, pois este fator iria motivá-los, o que com toda certeza geraria retornos financeiros à empresa, pois os funcionários que responderam que não estão satisfeitos com a realocação, poderiam estar em cargos nos quais sentiriam-se satisfeitos e motivados, ou seja, cargos de conformidade com as suas competências, apresentando assim bons resultados.

Através dos resultados da pesquisa se pode observar que os colaboradores que não foram treinados, que não são avaliados e preparados para a realocação irão apresentar um rendimento abaixo do que a organização espera gerando assim impactos econômicos para as empresas que não possuem um sistema de cargos e salários implementado. O principal objetivo deste sistema não é apenas motivar os funcionários para melhoria da remuneração, mas sim baseado no sentimento que reconhecimento e de valorização, o que de fato faz com que aumente a produtividade dos colaboradores.

Id en line Revista de Psicologia. Ano 7, No. 20, Julho/2013 - ISSN 1981-1179. 


\section{Considerações Finais}

É de suma importância para as organizações a implantação do Plano de Cargos e Carreiras e de um programa de treinamento e desenvolvimento do seu quadro de funcionários. No decorrer da realização deste trabalho de pesquisa, constatou-se que o impacto gerado pela sua falta, interfere em uma realocação adequada dos colaborados trazendo insatisfação a estes e dificultando sua adequação ao novo cargo, o que causa alta rotatividade e eleva os custos da organização com demissões e com recrutamento e seleção.

Observando-se a pesquisa realizada através de questionário, apesar das limitações na obtenção dos resultados, a organização que não possui um plano de cargos e salários e não investe em treinamento e desenvolvimento, faz com que seus funcionários sintam uma lacuna em relação ao seu futuro dentro da mesma, o que traz um sentimento de falta de perspectivas, pois, ao contratarem e ou realocarem seus colaboradores há dificuldade destes a se adaptarem à função interferindo negativamente nos resultados em seus produtos e serviços. Observou-se, inclusive, que a promoção sem o devido treinamento ao contrário do que antes se pensava, não traz satisfação e que todos os entrevistados indiscutivelmente manifestaram que se sentiriam valorizados e acolhidos caso houvesse o referido plano na organização da qual fazem parte.

Quando a empresa possui este plano organizado e definido, dá ao funcionário a possibilidade de planejar sua carreira dentro dela, sentindo-se estimulado a buscar melhorias para seu desenvolvimento e a se qualificar cada vez mais, gerando a melhoria contínua do seu capital intelectual e um sentimento de valorização que agregará à organização excelência aos produtos e serviços.

\section{Referências}

CARBONE, Pedro Paulo et al. Gestão por competências: gestão do conhecimento. $3^{\text {a }}$ edição São Paulo: Fgv-management, 2010. 196 p. (Gestão de pessoas).

CHIAVENATO, Idalberto. Indrodução à Teoria Geral da Administração. 7. ed. São Paulo: Elsevier, 2004. 128 p.

PASCHOAL, Luiz. Administração de cargos e salários: Manual prático e novas metodologias. $3^{\circ}$ Rio de Janeiro: Qualitymark, 2010. 
PAULA, Anderson Marciano de, et al. Estudo de um projeto de instalação de um plano de cargos e salários em uma empresa, UNIFIEO - Centro Universitário FIEO, Osasco, 02 de outubro de 2007.

\section{Sites consultados}

www.promerito.com.br 06 de maio de 2011 às 22:45.

www.maph.com.br/product_info.php?cPath=3\&products_id=76 09 de maio de 2011 às 23:00.

www.promerito.com.br 16 de maio de 2011 às 22:30.

www.artigonal.com/gestao-artigos/a-administração-de-recursos-humanos-1153930.html 15 de setembro de 2011 às 17:28.

www.guiarh.com.br/PAG21J.html 15 de setembro de 2011 às 17:50.

\section{Como citar este artigo (Formato ISO):}

MOTA, A.A.; CAMPELO, M.P.S.; ALMEIDA NETO, J.L. O impacto da sucessão de cargos na empresa. Id on Line Revista de Psicologia, Julho de 2013, vol.1, n.20, p. 64-74. ISSN 1981-1189. 